A third curve is also introduced which represents such a rotation of the system that the planet always shows the same face to the satellite, just as we always see the same face of the moon; this curve is called the curve of rigidity, because when the motion is of this kind, the system moves as though the planet and satellite were parts of one rigid body.

It appears from a consideration of these three curves that if the whole momentum of the system be less than a certain amount, then it is not possible to set a given planet and satellite in rotation, so that the planet shall always show the same face to the satellite; but if this can be done at all, it can be done in two ways, and one of those ways corresponds to a maximum amount of energy of the system, and the other to a minimum. Moreover the configuration of maximum energy is one of dynanical instability and the system may degrade in either of two ways from that state. In one of these modes of degradation the satellite approaches and falls into the planet, and in the other it recedes from the planet.

Part of the author's previous papers consists in tracing backwards the moon's motion from its present conditicn to that configuration of maximum energy; and it was found that that state corresponded with a rotation of the earth and moon, like the parts of one rigid body, in about five hours. This rapid periodic time of the moon corresponds with only a few thousands of miles intervening between the earth's surface and that body. Since the tides on the earth must be subject to friction, it follows inevitably that, if time enough has elapsed since the origin of the moon and earth, the present state must be a degradation of the configuration of maximum energy, which cannot itself be a degradation of a previous state. And therefore it was maintained that this closeness of the two bodies points to the community of their origin.

In this mode of evolution we see that the rotation and revolution of the two bodies was primitively such that the month and day were of equal length (about five hours), and that in the future they will again come to equality, each being then about fifty of our days long. From this it follows that the system must pass through some phase in which there is a maximum number of planetary rotations during one revolution of the satellite, or shortly there must, at some time, be a maximum number of days in the month. Numerical calculation shows that for the earth and moon that maximum number is about 29, and that at present, when we have $27 \frac{1}{3}$ days in the sidereal month, we have slightly passed that maximum.

From a further consideration of the figures it appears that if the planet and satellite are set in motion with opposite rotations, the satellite will fall into the planet if the moment of momentum of orbital motion be less than or equal to, or only greater, by a certain critical amount than the moment of momentum of planetary rotation; but if it be greater by more than a certain critical amount the satellite will approach the planet, the rotation of the planet will stop and reverse, and finally the system will come to equilibrium when the two bodies move round as a rigid body, with a long periodic time.

If the rate of the planet's rotation be less than that of the satellite's revolution, so that the sidereal month is shorter than the day (as with the inner satellite of Mars), then the satelite will either approach the planet and ultimately fall into it, or will approach the planet and will finally move round the planet at the same rate as the planet rotates. It depends on the nature of the system, as to which of these two cases will be the result.

The method is then extended to the case where the satellite, instead of being merely an attractive particle, is also a spheroid rotating about an axis perpendicular to the plane of the orbit. In this case the graphical illustration is by means of surfaces, there being one surface representing conservation of moment of momentum, and another representing the energy of the system. Each point on one surface has a corresponding point on the other surface, and the point on the energy surface must always slide down hill. It is not necessarily the case that the descent should be down a line of greatest slope. Illustrations are given to show that a point on an energy surface may sometimes depart from the bottom of a furrow, or may descend a ridge on the surface. The path to be followed by the point on the energy surface depends on the nature of the tides raised in the two bodies. Thus the solution in this case is not determinate, without some further knowledge of the system.

\section{MORE NOTES FROM KILBURN}

$T H E$ gas and petroleum-engines make a fair show. The Otto silent gas-engine, however, seems still to hold its own, other constructions having, so far as one can judge from a short inspection at Kilburn, some defect or other, such as noisy working, or a dangerouslooking outside flare of the ignited gas. One striking novelty is shown in this section, namely, an invention of Mr. Iugald Clerk, whereby the gaseous mixture is. lighted by a cage of platinum wire, which retains heat enough from one ignition to the next to be effective for this purpose. It is stated that 400 ignitions have been made in the cylinder of an engine of this type in one minute. There are other distinctive contrivances in this gas-engine, which, by the by, is the manufacture of Messrs. Thomson, Sterne, and Co., and altogether show.s great ingenuity. One of the engines exhibited by this frrm is described as a "Domestic Motor," of $\frac{3}{10}$ horsepower, costing but $15 l$, and deriving its power from steam generated by the ignition of air and gas. Such an engine seems admirably fitted for private use in laboratories and small workshops as well as in houses.

Self-binding harvesters, in which wire is used for the automatic tying-up of the sheaves, are attracting much attention, now that millers have ajopted the use of magnets, preferably electro-magnets, to separate any bits of iron wire that may happen to get mixed with the grain.

The machinery and implements employed in buttermaking and cheese-making afford a striking example of the advantages resulting from the application of scientific exactness to a most useful art. The question of temperature in every operation of the dairy is now recognised as of extreme importance. The thermometer reigns supreme in the interesting tent where dairying is shown. The material, the depth, and the diameter of the pans for "setting" milk have been duly studied. Though the processes and instruments exhibited in action are few in comparison with those at the previous shows at Hamburg and other special gatherings, yet the exhibits of Mr. E. Ahlborn and of the Aylesbury Dairy Company are worth attentive study. We noted especially an ingenious butter-squeezer or presser, which removes in the most effectual way that very variable and often excessive quantity of butter-milk and water and of interstitial air which occur in ordinary butter, even when quite genuine. Not only is liability to change and decomposition much lessened by this operation, but constancy of composition is secured, and we no longer find the proportion of water in fresh butter ranging between 6 and 20 per cent.

Messrs. F. H. Atkins and Co. show some good models and examples of their water-filters and other sanitary appliances in connection with water supply, One of their contrivances is specially clever. The surfaces of filtering media of course become rapidly clogged and useless when media of course become rapidly clogged The vertical surfaces of Atkins's cloth filters are so arranged as to be capable of rotation against a rotating cylindrical brush, set vertically, and accommodating itself perfectly to the surface to be cleansed.

An instructive section of the Killurn Show is that deroted to hops. From a paper issued by Messrs. John 
Barth and Sons, of Nuremberg, we glean some interesting data as to the hop production of the world; this firm also exhibits a diagram of hop-prices from 1798 to 1878 . Some samples of hops preserved for two years or more by a process, of which the nature is kept secret, are perfect in aroma and colour. Compression, cold, and exclusion of air are elements of the process but do not suffice to account for its success. The total amount of hops grown in the world in 1878 is stated by Messrs. Barth to be-

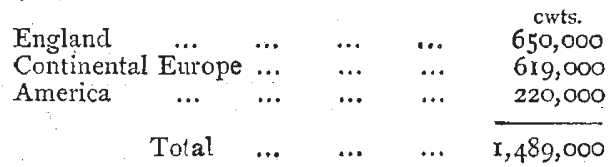

Many most instructive data as well as specimens, models, and instruments, frequently showing novel applications of scientific principles, may be studied at the Kilburn Show. We had noted for remark the malt-cake exhibited on Stand 586, and the splendid collection of seeds, roots, and models shown by Sutton and Sons of Reading, but the limit of the space at our disposal preclude us from further dwelling upon this exhibition, with its perplexing but most interesting collections.

\section{OUR ASTRONOMICAL COLUMN}

The New COMET (SWift, JUNE 20).-From observations at Strasburg by Prof. Winnecke on June 21,26 , and July 2, Dr. Kuistner, one of his pupils, has computed the following elements of this comet, taking account of all the small corrections:-

Perihelion passage, 1879, April 27.3357 M.T. at Berlin.

\begin{tabular}{|c|c|c|}
\hline & & \\
\hline $\begin{array}{l}\text { Longitude of perihelion } \ldots \\
\text { ascending node }\end{array}$ & ․ $42 \quad 2830^{\circ}$ & Mean eq \\
\hline $\begin{array}{c}\text { nation to ecliptic ... } \\
\text { perihelion distance }\end{array}$ & $\left.\begin{array}{llll}\cdots & 45 & 35 & 30 \\
\cdots & 72 & 59 & 52 \cdot 5\end{array}\right\}$ & $79^{\circ} \mathrm{O}$ \\
\hline perihelion distance ... & $\begin{array}{l}\text {.. } 9.948935 \\
\text { etrograde. }\end{array}$ & \\
\hline
\end{tabular}

From this orbit it appears that on Tuesday next, July 15 , the comet will make an exceedingly close approach to the pole of the equator; at Ioh. G.M.T. its calculated position is in right ascension $15 \mathrm{~h} .20 \mathrm{~m}$, and declination $89^{\circ} 42^{\prime}$, but earlier in the evening its distance from the pole may be little over $10^{\prime}$.

We extract the following positions from an ephemeris for Berlin midnight, communicated by Prof. Winnecke :-

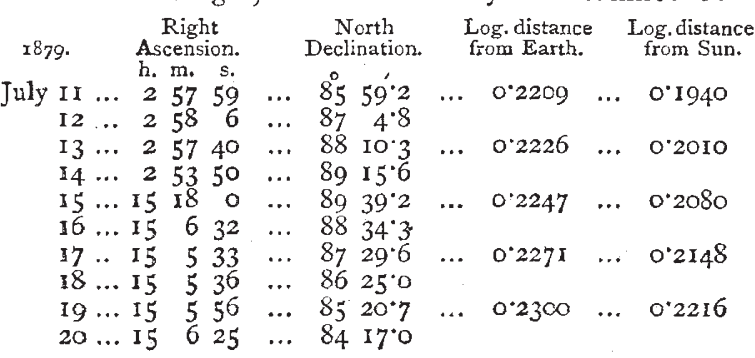

TEMPEL's COMET, 1867 II.-In a letter addressed to The Observatory, communicating his observations of this comet made during the present reappearance, at Florence, Dr. Tempel remarks:" "Since it will approach Jupiter nearer in the year I 882 than in the year 1870 , we shall probably have difficulty in seeing it again, if we ever do so." This statement must rest upon some misconception or error of calculation. The mean daily motion at the perihelion passage in the present year would not differ materially from $593^{\prime \prime} \cdot 18$ as fixed by M. Raoul Gautier, and the perihelion passage having taken place about May 6.98 G.M.T., it will appear that when the comet is next in aphelion (which is about the nearest point of approach to the orbit of Jupiter) early in May, I882, the actual distance between the two bodies is rather more than $0: 75$ of the earth's mean distance from the sun, though in the actual orbit it might happen that at this point the comet and planet approach within $0 * 3$. Neglecting the effect of perturbation in the interim, it will be found from $\mathbf{M}_{\text {. }}$ Gautier's elements that the nearest approach of the comet to Jujiter during the next revolution will occur in October I88I, when their mutual distance will be rather less than 0 58. In January I870, according to Dr. Seeliger's computation this distance was only $0^{\circ} 32$. Although, therefore, the perturbations during the ensuing revolution may be very sensible, they will not produce so great an effect upon the elements of 1879 as to bear out Dr. Tempel's statement.

Observations of this comet have been made at the Observatory of Rio de Janeiro, where the comet was found independently by M. Cruls. The Emperor of Brazil, who appears to take a personal interest in the proceedings of his astronomical establishment, has communicated these observations to the Paris Academy of Sciences, of which his Majesty is a Corresponding Member.

The VARIABLe-STaR PIAzzI XIII. I26.-Mr. Burnham draws attention to an interesting discovery he has made respecting this object, viz., that it is really a close double star, the components of nearly equal magnitude 6.2 and 6.5 , at a central distance of $0^{\prime \prime} \cdot 48$ on an angle of $80^{\circ} .4$ for $1879^{\circ} 4$. Attention was first directed to its variability by Dr. Julius Schmidt, of Athens, in June, I 866. On the 6 th of that month he found it $54 \mathrm{~m}$. more conspicuous than $i$ Virginis, with a yellowish white light contrasting with the orange tinge of the latter star. Piazzi estimated it $6.7 \mathrm{~m}$. and $7 \mathrm{~m}$, not $8 \mathrm{~m}$., as given in his Catalogue ; Lalande called it $6 \%$, Brisbane 6 , Heis $6 \%$, and it is $7 \mathrm{~m}$. on Bremicker's chart; it is No. 1,342 of Lamont, who estimated it only $8 \mathrm{~m}$. It is worthy of note that the star occurs in the Uranometry of Al Sufi, translated by Prof. Schjellerup in 1874 ; it is No. I9 of the constellation Virgo in the catalogue of the Persian astronomer, and rated $5.6 \mathrm{~m}$. As Mr. Burnham remarks, it will be easy to determine which, if only one, of the stars is variable. The star is B.A.C. 4,53I and No. I, 244 of the new Greenwich Nine-Year Catalogue. Its position for $1880^{\circ} 0$ is in R.A. 13 h. $28 \mathrm{~m}$. I8s., N.P.D. $102^{\circ} 35^{\circ} 9$.

\section{GEOGRAPHICAL NOTES}

A PRIVATE letter received at Carlscrona from the commander of the steamer $V e g a$ reports all on board in good health. The Vega left the mouth of the Lena on August 27. At first she made tolerably good progress, although she had to contend with ice and shoals. The voyage was continued to Cape Yakow, but there she was stopped for three days. The steamer got away from there on September II, and after a difficult passage reached Cape North on the I3th, where she remained beset until the I 8th. After that date the steamer could only now and then make progress on account of the ice. On September 28 the expedition attained this present position, which is situated in lat. $67^{\circ} 6^{\prime}$, long. $173^{\circ} 30^{\prime}$. If the $V e g a$ had got there two days earlier she would have reached Behring Straits. The ship is not lying in a harbour, but alongside a very low sandy shore, made fast to the ground ice. Every one was well, and there was a good supply of provisions and enough coal on board to steam 2,000 miles, One or two villages had been passed, the inhabitants of which are Tschutsches. Their complexion is tawny and their hair and eyes are black. They dress in clothes made of reindeer skin, reside in skin tents, and live on seal blubber. They are singularly amiable and obliging; the women bave their faces tattooed, but the men have not. Their language is very hard to understand, but 